\title{
The 2S2P1D: An Excellent Linear Viscoelastic Model
}

\author{
Md. Yusoff ${ }^{1}$, N. I., Monieur, D. ${ }^{2}$, Airey, G. D. ${ }^{1}$
}

\begin{abstract}
An experimental campaign has been carried out on five different unaged and five aged penetration grade bitumens to determine the properties of the 2S2P1D (combinations of two springs, two parabolic elements and one dashpot) model. The dynamic oscillatory test was conducted in order to obtain the rheological data using the dynamic shear rheometer (DSR). Earlier, the samples were aged following the Rolling Thin Film Oven Test (RTOFT) test procedure. It was found that the 2S2P1D model which consists of seven parameters simulates in an excellent way the linear viscoelastic properties of aged and unaged penetration grade bitumens over a wide range of temperatures and frequencies. The goodness of fit statistical analysis showed that the model had a good correlation and comparable to the measured dynamic data.
\end{abstract}

Keywords: 2S2P1D model, complex modulus, phase angle, linear viscoelastic

\section{INTRODUCTION}

heology, by definition, is the study of the flow and deformation of matter under the influence of an applied stress. Regarding the bitumen, the response to a stress is both dependent on temperature and loading time and consequently the

rheology of bitumen can be expressed by its stress-strain-time-temperature response. Several regions of behaviour exist for penetration grade bitumen, and they are mainly determined by parameters like the strain $(\varepsilon)$, the temperature $(T)$ and the time of loading $(t)$. When performing dynamic tests like with the dynamic shear rheometer (DSR), the complex modulus $\left|G^{*}\right|$ is used. The $\left|G^{*}\right|$ is a complex number, which real part is the storage modulus, $G^{\prime}$ representing the elastic component of the bitumen; it describes the amount of energy that is stored and released elastically in each oscillation. The imaginary part of $\left|G^{*}\right|$ is the loss modulus, $G^{\prime \prime}$ which represents the viscous component of the material; it is described as the out of phase component of $\left|G^{*}\right|$. The phase angle, $\delta$ of this complex number can be used to analyze the viscoelastic behaviour. Obviously, the $\left|G^{*}\right|$ and the $\delta$ of a bitumen are dependent on the temperature and the frequency (time of loading) can be shown in the following expressions [1], [2]:

$$
\begin{aligned}
& \left|G^{*}\right|=\sqrt{\left(G^{\prime}\right)^{2}+\left(G^{\prime \prime}\right)^{2}} \\
& \tan \delta=\frac{G^{\prime \prime}}{G^{\prime}}
\end{aligned}
$$

The data representation of a dynamic test is based on the time temperature superposition principle (TTSP). The amount of shifting required at each temperature to form the master curve is termed the shift factors, $a_{T}$. Measurements of the dynamic data at different frequencies and temperatures can be represented with one curve called master curve, usually plotted against frequency and using a reference temperature $\left(T_{\text {ref }}\right)$, after having shifted the different parts of the curve. The $\left|G^{*}\right|$ and $\delta$ data can be predicted by means of mathematical and mechanical models.

Among the models observed from the literature, the 2S2P1D model was found to be a unique model where it capable of predicting both the rheological properties of bitumens and asphalt mixtures. Moreover, the model's parameters bring a

1 Student, Nottingham Transportation Engineering Centre, School of Civil Engineering, University of Nottingham, NG7 2RD Nottingham, United Kingdom (evxnim@nottingham.ac.uk)

2 Student, Department Genie Civil et Batiment, Ecole Nationale des TPE, Rue Maurice Audén, F-69518 Vaulx-en-Velin Cedex, Lyon, France (damien.mounier@gmail.com)

3 Professor, Nottingham Transportation Engineering Centre, School of Civil Engineering, University of Nottingham, NG7 2RD Nottingham, United Kingdom (evzgda@nottingham.ac.uk) 
significant physical meaning. Therefore, this study is conducted to investigate the ability of the 2S2P1D model in predicting the linear viscoelastic properties of aged and unaged penetration grade bitumens data, collected using the dynamic shear rheometer (DSR) instrument. The correlations between measured and predicted values were then evaluated using the goodness of fitting statistical analysis.

\section{THE 2S2P1D MODEL}

The 2S2P1D, combinations of two springs, two parabolic creep elements and one dashpot, is a unique rheological model to predict the linear viscoelastic properties for bitumens and asphalt mixtures [3], [4]. The model's elements representation can be shown in figure 1.

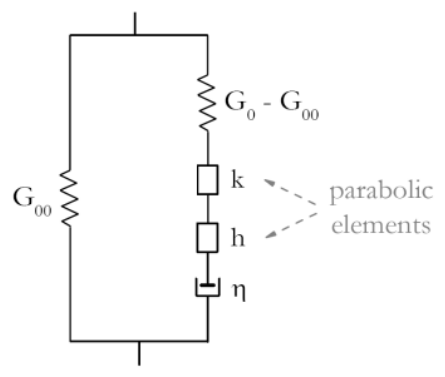

Figure 1: The 2S2P1D Model [5]

The introduced model consists of seven parameters and the $\left|G^{*}\right|$ is translated in the following mathematical expression:

$$
G^{*}=G_{o o}+\frac{G_{o}-G_{o o}}{1+\delta(i \omega \tau)^{k}+(i \omega \tau)^{h}+(i \omega \beta \tau)^{1}}
$$

where $i$ is complex number defined by $i^{2}=-1, \omega$ is frequency ( $\mathrm{Hz}$ or $\left.\mathrm{rad} / \mathrm{s}\right), k$ and $h$ are exponents with $0<k<h<1, \delta$ is constant, $G_{o}$ is the static modulus when $\omega \rightarrow$ zero, $G_{o o}$ is the glassy modulus when $\omega \rightarrow$ infinity, $\beta$ is constant, defined by $\eta=$ $\left(G_{o}-G_{o o}\right) \beta \tau, \eta$ is Newtonian viscosity and $\tau$ is characteristic time, function of temperature.

\section{EXPERIMENTAL DESIGN}

\section{Materials}

Five different penetration grades of bitumens namely as 10/20, 35/50, 40/60, 70/100 and 160/220 used in this study. The bitumens 10/20 and 160/220 represent the hardest and softest penetration grades, respectively.

\section{Dynamic Shear Rheometer}

The dynamic tests have been conducted using the Bohlin Gemini controlled strain DSR (Figure 2a). The DSR is set by two plates sandwiching the bitumen. Both plates have the same dimensions, but the bottom one is fixed whereas the upper one is mounted on an axis allowing it to rotating. The dynamic tests reported in this study were performed under the following test conditions:

- Mode of loading : controlled strain

- Temperature $\quad: 10$ to $80^{\circ} \mathrm{C}$ (with the interval of $5^{\circ} \mathrm{C}$ )

- Frequencies : :0.01 to $10 \mathrm{~Hz}$

- Spindle geometries : $8 \mathrm{~mm}$ (diameter) and $2 \mathrm{~mm}$ gap $\left(10-35^{\circ} \mathrm{C}\right)$ and $25 \mathrm{~mm}$ (diameter) and $1 \mathrm{~mm}$ gap $\left(25-80^{\circ} \mathrm{C}\right)$

- Strain amplitude $\quad$ : within linear viscoelastic (LVE) response dependent on $\left|G^{*}\right|$ of each materials used

The amplitude sweeps were used to determine the limit of the LVE response based on the point where $\left|G^{*}\right|$ had decreased to $95 \%$ of its initial value [1]. In this study, the $T_{\text {ref }}$ was arbitrarily taken as $10^{\circ} \mathrm{C}$ for the construction of the master curve and without assuming any functions for the shift factor, the curve is manually shifted.

\section{Rolling Thin Film Oven Test (RTFOT)}

The Rolling Thin Film Oven Test (RTFOT) simulates a short term ageing which occurs during the building of a road. In this test, 8 glasses contain $35 \mathrm{~g}$ of bitumen each are fixed in a vertically rotary carriage at a speed of 15 revolution/min (Figure 2b). Hot air is blown periodically in each glass, at a flow of $4000 \mathrm{ml} / \mathrm{min}$, usually at its lowest position. During the test, the bitumen continuously flows around the inner surface of the glass in thin films of around $1.25 \mathrm{~mm}$. The standard testing procedure is to set the temperature at $163^{\circ} \mathrm{C}$, and to let the test runs for 75 minutes [5]. However, a different manner has been applied in this study, because several testing times have been carried out in the following order: $1 \mathrm{~h}-1 \mathrm{~h} 15 \mathrm{~min}-1 \mathrm{~h} 30 \mathrm{~min}-$ 
$3 \mathrm{~h}-5 \mathrm{~h}-7 \mathrm{~h}$. This method ensures that all the bitumen is exposed to heat and air, and it simulates well the volatilization and oxidation of bitumen that are the main reasons of short term ageing. After RTFOT, the aged bitumen are poured into vials and tested with the DSR instrument. However, it should be born in mind only bitumen 160/220 was engaged with ageing test.
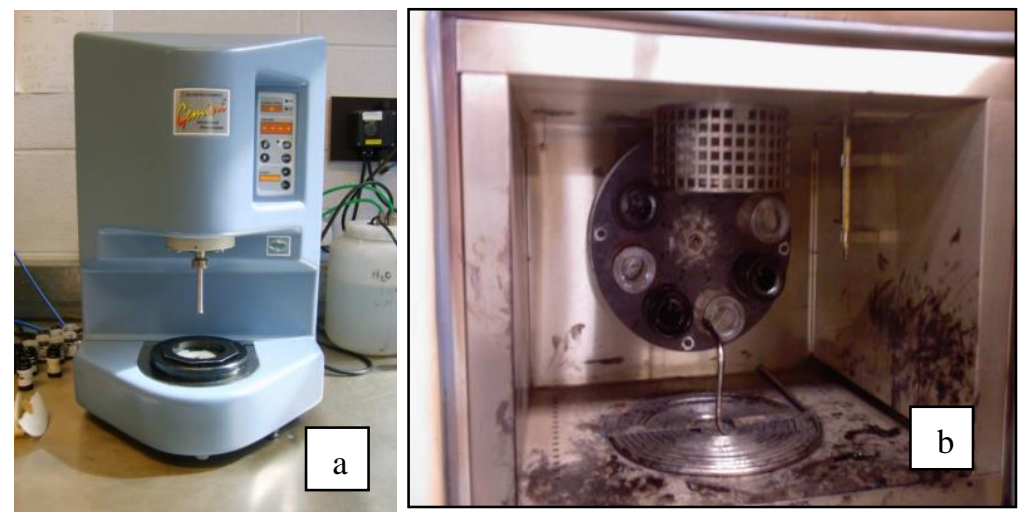

Figure 2: (a) The DSR body and (b) RTFOT oven

\section{Goodness of Fit}

The standard error of estimation, $S_{e}$ and standard error of deviation, $S_{y}$ can be defined as the following:

$$
\begin{aligned}
& S_{e}=\sqrt{\frac{\sum(Y-\hat{Y})^{2}}{(n-k)}} \\
& S_{y}=\sqrt{\frac{\sum(Y-\bar{Y})^{2}}{(n-1)}}
\end{aligned}
$$

where $n$ is sample size, $k$ is number of independent variables in the model, $Y$ is tested modulus, $\hat{Y}$ is predicted modulus and $\bar{Y}$ is mean value of tested modulus. The small value shows better the prediction. Meanwhile the coefficient of correlation, $R^{2}$ can be shown as follows:

$$
R^{2}=1-\frac{(n-k)}{(n-1)} x\left(\frac{S_{e}}{S_{y}}\right)^{2}
$$

For the perfect fit, $R^{2}=1$. The criteria for the goodness of fit statistic parameters are shown in table 1 [6]:

Table 1: Criteria for goodness of fit statistics

\begin{tabular}{c|c|c}
\hline Criteria & $R^{2}$ & $S_{e} / S_{y}$ \\
\hline Excellent & $\geq 0.90$ & $\leq 0.35$ \\
Good & $0.70-0.89$ & $0.36-0.55$ \\
Fair & $0.40-0.69$ & $0.56-0.75$ \\
Poor & $0.20-0.39$ & $0.76-0.89$ \\
Very Poor & $\leq 0.19$ & $\geq 0.90$ \\
\hline
\end{tabular}

\section{RESULTS AND DISCUSSION}

\section{Amplitude Sweep Test}

The temperatures of the amplitude sweep test are taken close to the lowest temperature of each testing geometry because the linear limit of the material seems to decrease with the temperature. Table 1 shows the linear viscoelastic strain limit obtained from each samples using the $8 \mathrm{~mm}$ spindle at $10^{\circ} \mathrm{C}$ and $25 \mathrm{~mm}$ spindle at $40^{\circ} \mathrm{C}$, respectively. To ensure that the test was conducted in the linear viscoelastic region, a target strain from $8 \mathrm{~mm}$ spindle at $10^{\circ} \mathrm{C}$ was selected for all the experiments.

Table 2: Linear Viscoelastic Strain Limits

\begin{tabular}{c|c|c|c|c|c}
\hline Pen. Grade & $10 / 20$. & $35 / 50$ & $40 / 60$ & $70 / 100$ & $160 / 220$ \\
\hline $8 \mathrm{~mm}$ at $10^{\circ} \mathrm{C}$ & $1.6 \%$ & $0.8 \%$ & $1.3 \%$ & $1.0 \%$ & $1.5 \%$ \\
$25 \mathrm{~mm}$ at $40^{\circ} \mathrm{C}$ & $3.0 \%$ & $1.0 \%$ & $2.0 \%$ & $2.0 \%$ & $4.0 \%$ \\
\hline
\end{tabular}




\section{Frequency Sweep Test}

The $\left|G^{*}\right|$ and $\delta$ master curves for five different penetration grade bitumens are all similar in shape and therefore, the result will only be presented for bitumen 10/20 in figure 3 with the understanding that the commentary applies to all five different bitumens.
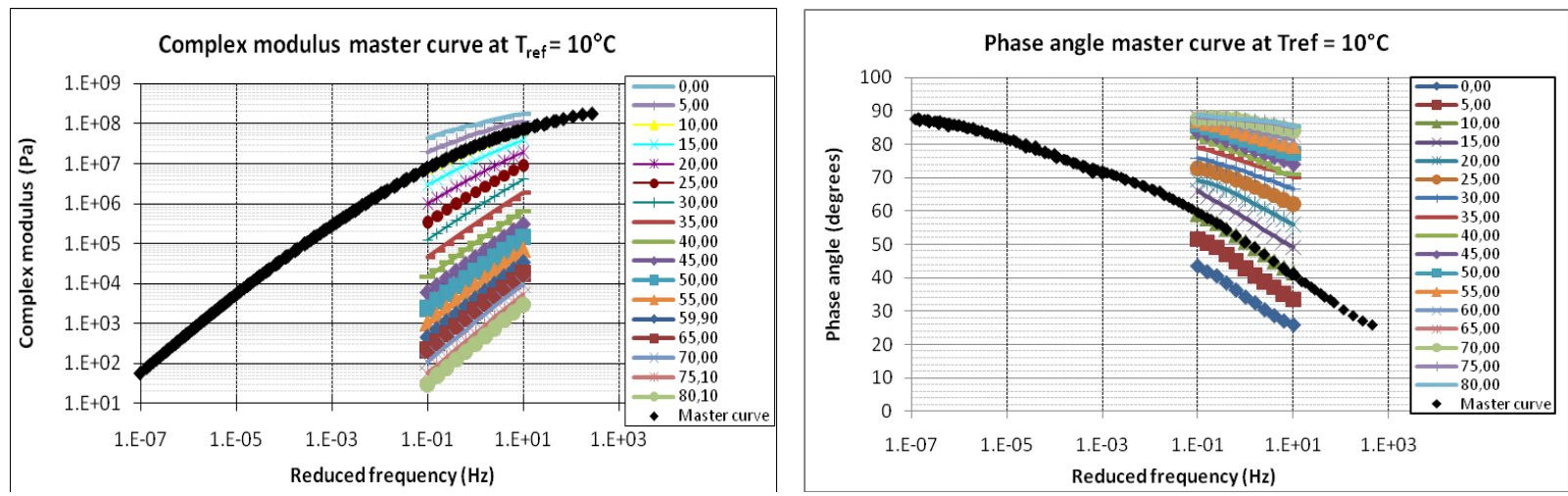

Figure 3: The $\left|G^{*}\right|$ and $\delta$ Master Curves

The penetration grade bitumens generally can be classified as "thermorheologically simple" materials with their rheological properties being temperature and time equivalent provided that they are determined within the linear viscoelastic region [2]. Moreover, the Black diagram, graph of the magnitude (norm) of the $\left|G^{*}\right|$ versus $\delta$ obtained from the dynamic tests, are unique. This curve, however, did not show here for brevity. The five $\left|G^{*}\right|$ master curves of these conventional bitumens reach a limiting value, called the glassy modulus, $G_{o o}$ between $0.5 \mathrm{GPa}$ and $1 \mathrm{GPa}$, depending on the hardness of specimen. The bitumen 10/20 was observed to have the lowest $G_{o o}$. This phenomenon could attribute to the compliance error problem from the DSR instrument. All the samples are behaving as the Newtonian flow at high temperatures and low frequencies.

\section{Ageing Effect}

Figure 4 show the effect of ageing on the $\left|G^{*}\right|$ and $\delta$ master curves. A consistent increase in stiffness with the ageing time can be observed particularly for low frequencies and high temperatures. The $G_{o o}$ seems to remain the same for all the aged bitumens. However, it can be noticed a decrease of the $\delta$ in the master curve (Figure 4), which correspond to an increased of elastic behaviour after ageing. It is also interesting to compute the ageing index (AI), which is presented below for a typical temperature of $25^{\circ} \mathrm{C}$ and a frequency of $0.4 \mathrm{~Hz}$. On the other hand, table 3 shows ageing increases the $\left|G^{*}\right|$ and decreases the $\delta$ (increase of stiffness and elastic behaviour). The AI effect on the $\delta$, however, is less compare to the $\left|G^{*}\right|$.
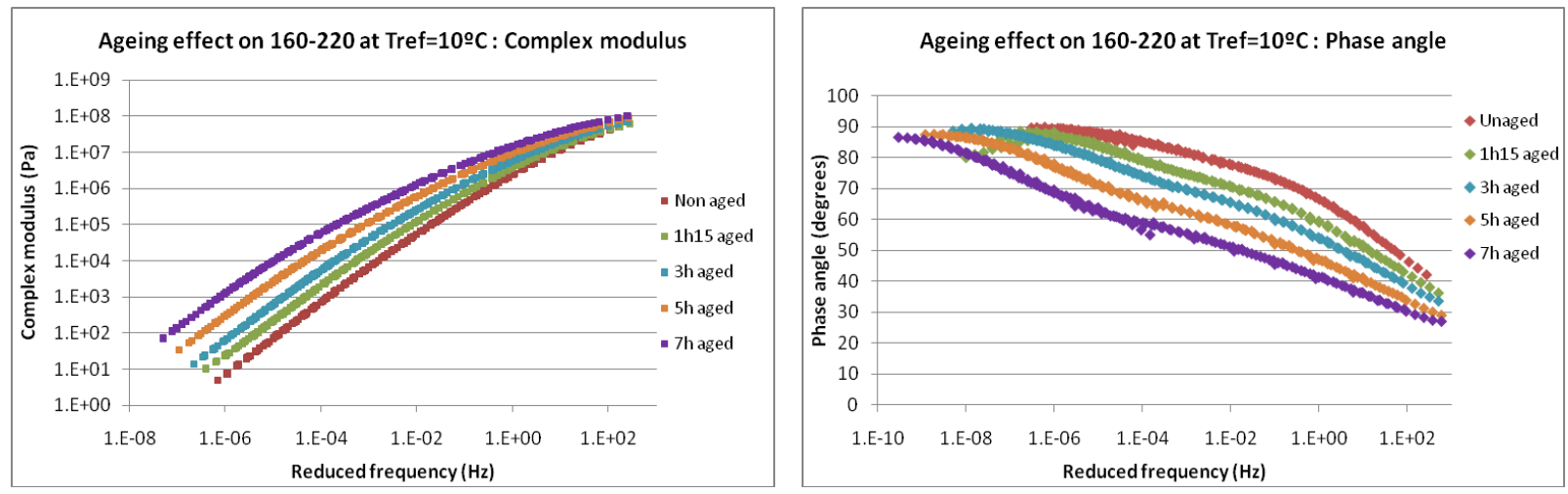

Figure 4: Effect of Ageing on the $\left|G^{*}\right|$ and $\delta$ Master Curves

Table 3: Ageing Index (AI) at $25^{\circ} \mathrm{C}$ and $0.4 \mathrm{~Hz}$

\begin{tabular}{c|c|c|c|c}
\hline Sample & $\left|G^{*}\right|(\mathrm{Pa})$ & $\delta\left({ }^{\circ} \mathrm{C}\right)$ & $\left|G^{*}\right|_{\text {aged }}\left|G^{*}\right|_{\text {unaged }}$ & $\delta_{\text {aged }} / \delta_{\text {unaged }}$ \\
\hline unaged bitumen & 52660 & 79.44 & - & - \\
1h 15 aged & 92377 & 73.51 & 1.75 & 0.93 \\
3h aged & 187980 & 68.80 & 3.57 & 0.87 \\
5h aged & 400440 & 62.15 & 7.60 & 0.78 \\
7h aged & 835730 & 55.79 & 15.87 & 0.70 \\
\hline
\end{tabular}




\section{Modeling the Unaged Bitumens}

The 2S2P1D model was calibrated for every sample using the $\left|G^{*}\right|$ data at $10^{\circ} \mathrm{C}$. The calibration process was done manually using the MS Excel spreadsheet. Table 4 shows the 2S2P1D model parameters for all the samples studied. Meanwhile the $\left|G^{*}\right|$ master curves can be depicted as in figure 4.

Table 4: The 2S2P1D parameters

\begin{tabular}{c|c|c|c|c|c|c|c}
\hline Pen Grade & $G_{o o}(\mathrm{~Pa})$ & $\mathrm{G}_{o}(\mathrm{~Pa})$ & $k$ & $h$ & $\delta$ & $\tau$ & $\beta$ \\
\hline $10 / 20$ & 0 & $1.00 \mathrm{E}+09$ & 0.22 & 0.64 & 4.0 & $6.00 \mathrm{E}-03$ & 90 \\
$35 / 50$ & 0 & $1.00 \mathrm{E}+09$ & 0.22 & 0.64 & 4.0 & $1.50 \mathrm{E}-03$ & 75 \\
$40 / 60$ & 0 & $1.00 \mathrm{E}+09$ & 0.22 & 0.64 & 4.0 & $3.00 \mathrm{E}-04$ & 90 \\
$70 / 100$ & 0 & $1.00 \mathrm{E}+09$ & 0.22 & 0.64 & 4.0 & $6.00 \mathrm{E}-05$ & 90 \\
$160 / 220$ & 0 & $1.00 \mathrm{E}+09$ & 0.22 & 0.64 & 4.0 & $3.50 \mathrm{E}-05$ & 45 \\
\hline
\end{tabular}

It is worth noting out that several combinations can be made using the 2S2P1D model since there is no unique combination of the parameters can be presented and several combinations can fit with more or less well with the experimental data. It has been noticed that the goodness of fitting of predicted model depends on the initial value of the $G_{o o}$ with a rather good fitting can be found when $G_{o o}$ between $0.5 \mathrm{GPa}$ and $2 \mathrm{GPa}$. Christensen and Anderson [7] suggested the $G_{o o}$ can be taken as $1 \mathrm{GPa}$ for most engineering purposes. Airey [2] and $\mathrm{Lu}$ et al. [8] suggested using the value between $1 \mathrm{GPa}$ to $2 \mathrm{GPa}$. In general, all samples tend to depict Newtonian flow behaviour at low frequencies and high temperatures. The $G_{o}$ is equal to zero and only six parameters of the model are needed to be determined. The $k, h$ and $\delta$, in addition, can be taken as similar for all samples, regardless the source and penetration grades of bitumens used. It was found that the $\beta$ values for bitumen 10/20, 40/60 and $70 / 100$ are similar due to the fact that they have similar slope at low frequencies and high temperatures. As expected, the bitumen $10 / 20$ with the lowest viscosity has smallest $\beta$. The $\beta$ was found to be associated with asphaltene (polar molecules) content where the $\beta$ value increases when the asphaltene content is elevated.

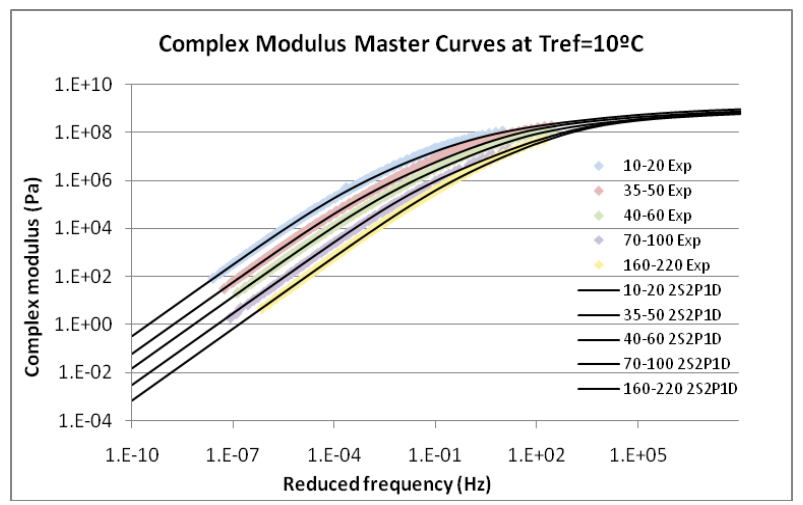

Figure 5: $\left|G^{*}\right|$ Master Curves for All Samples

\section{Modeling the Aged Bitumens}

Table 5 shows an ageing effect on the 2S2P1D model parameters. It can be seen that many of the parameters remain the same after ageing. The $G_{o}$ which is still equal to zero as binders are concerned, the glassy modulus $G_{o o}$, and the two parameters $k$ and $h$ remain similar after ageing. According to Delaporte et al. [4], the parameters like $h, k$ and $\delta$ are completely determined by the unaged bitumens, so they should remain the same after ageing process. However, it was observed that $\delta$ values were not in good agreement with Delaporte et al., because it can be noticed a slight increase from 2.3 for the raw binder to 5.5 for the most aged bitumen ( 7 hours). That problem, like 10/20, may associates with the compliance error problem from the rheometer instrument. The $\left|G^{*}\right|$ and $\delta$ master curves for the unaged and aged bitumens $160 / 220$ can be shown in figure 6.

Table 5: The 2S2P1D parameters of unaged and aged bitumen 160/220

\begin{tabular}{c|c|c|c|c|c|c|c}
\hline Ageing time $(\mathrm{h})$ & $G_{o}(\mathrm{~Pa})$ & $G_{o o}(\mathrm{GPa})$ & $k$ & $h$ & $\delta$ & $\tau$ & $\beta$ \\
\hline Unaged & 0 & 0.8 & 0.25 & 0.64 & 2.3 & $3.00 \mathrm{E}-05$ & 45 \\
1h 15min & 0 & 0.8 & 0.25 & 0.64 & 3.5 & $5.00 \mathrm{E}-05$ & 100 \\
$3 \mathrm{~h}$ & 0 & 0.8 & 0.25 & 0.64 & 4.0 & $8.00 \mathrm{E}-05$ & 160 \\
$5 \mathrm{~h}$ & 0 & 0.8 & 0.25 & 0.64 & 4.5 & $2.50 \mathrm{E}-04$ & 260 \\
$7 \mathrm{~h}$ & 0 & 0.8 & 0.25 & 0.64 & 5.5 & $8.00 \mathrm{E}-04$ & 400 \\
\hline
\end{tabular}



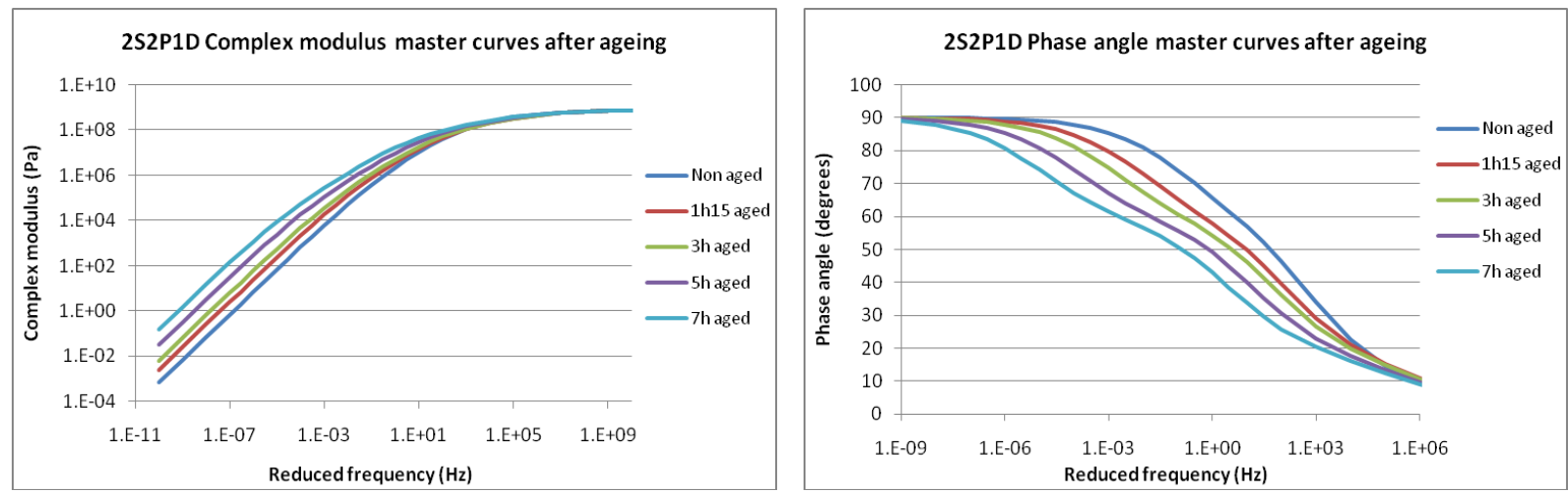

Figure 6: $\left|G^{*}\right|$ and $\delta$ Master Curves using the 2S2P1D Model

\section{Statistical Analysis}

A comparison between the goodness of fitting statistical analysis including $S_{e}, S_{e} / S_{y}$ and $R^{2}$ are shown in table 6 . It can be inferred that an excellent correlation has been observed between the measured and predicted $\left|G^{*}\right|$ data, where the 2S2P1D model simulates the linear viscoelastic properties of unaged bitumens over a wide range of frequencies and temperatures excellently. Similar observation has been made for aged $\left|G^{*}\right|$, however the table did not show here for the sake of brevity.

Table 6: Goodness of Fitting Statistical Analysis

\begin{tabular}{c|c|c|c|c|c}
\hline Pen. Grade & $S_{e}$ & $S_{e} / S_{y}$ & Criteria & $R^{2}$ & Criteria \\
\hline $10 / 20$ & $3.13 \mathrm{E}+06$ & 0.1310 & Excellent & 0.9858 & Excellent \\
$35 / 50$ & $7.75 \mathrm{E}+06$ & 0.2012 & Excellent & 0.9665 & Excellent \\
$40 / 60$ & $3.66 \mathrm{E}+06$ & 0.1415 & Excellent & 0.9834 & Excellent \\
$70 / 100$ & $6.65 \mathrm{E}+05$ & 0.1702 & Excellent & 0.9760 & Excellent \\
$160 / 220$ & $4.95 \mathrm{E}+05$ & 0.0508 & Excellent & 0.9979 & Excellent \\
\hline
\end{tabular}

\section{CONCLUSIONS}

Several conclusions can be drawn from this study;

- The 2S2P1D model is quite simple in its formulation, as a combination of springs, dashpot and parabolic elements. The calibration of the model is not a very difficult task and the model can then provide very good modelling of the bitumen within a large range of frequencies and temperatures.

- Bitumen ageing provokes a hardening at low frequencies (high temperatures) and an increase of its elastic behaviour. The effect on the 2S2P1D parameters is mainly an increase of the value of $\beta$, which is linked to the viscosity of the bitumen. It is also important to notice that the parameters $h, k$ and $\delta$ are completely determined by the pure bitumen and do not affected by ageing process. The results showed a slight change of $\delta$ after ageing, but this was certainly due to a compliance problem.

- The DSR instrument provides very accurate results, but there are some limitations. Some small problems have been encountered, but they did not affect the measurements. The compliance problem is not to be neglected, and can distort some measurements with a decrease of the complex modulus for stiff bitumen and lower temperatures.

- Regarding the glassy modulus of the bitumen, it is difficult to determine, and different values of it provides different combinations of the 2S2P1D parameters. The glassy modulus is an important parameter for the calibration of the 2S2P1D model because it governs the other parameter values.

\section{REFERENCES}

[1] G. D. Airey. "Rheological characteristics of polymer modified and aged bitumens", PhD Thesis, University of Nottingham, 1997

[2] G. D. Airey. "Use of Black diagrams to identify inconsistencies in rheological data", International Journal of Road Materials and Pavement Design, Vol. 3, No. 4, 2002. pp. 403 - 424

[3] F. Olard and H. di Benedetto. "General "2S2P1D" model and relation between the linear viscoelastic behaviours of bituminous binders and mixes", Road Material and Pavement Design, vol. 4, 2003. pp. 185 - 224

[4] B. Delaporte, H. di Benedetto, P. Chaverot, and G. Gauthier. "Linear viscoelastic properties of bituminous materials: from Binders to Mastics", Journal of the Association of Asphalt Paving Technologists, vol. 76, 2007. pp. 455 - 494 
[5] G. D. Airey. "State of the art report on ageing test methods for bituminous pavement materials", International Journal of Pavement Engineering, Vol. 4, No. 3, 2003. pp 165-176.

[6] N. H. Tran and K. D. Hall. "Evaluating the predictive equation in determining dynamic moduli of typical asphalt mixtures used in Arkansas", Journal of Association of Asphalt Paving Technologists, vol. 74, 2005 (CD ROM)

[7] D. W. Christensen and D. A. Anderson. "Interpretation of dynamic mechanical test data for paving grade asphalt" Journal of the Association of Asphalt Paving Technologists, vol. 61, 1992. pp. $67-116$

[8] X. Lu, U. Isacsson, and J. Ekblad. "Low-temperature properties of styrene-butadiene-styrene polymer modified bitumens", Construction and Building Materials, vol. 12, 1998. pp. 405 - 414 